\title{
Disaster Preparedness
}

for Natural Hazards

\section{Current Status in Bangladesh}

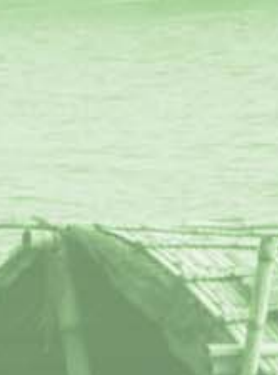

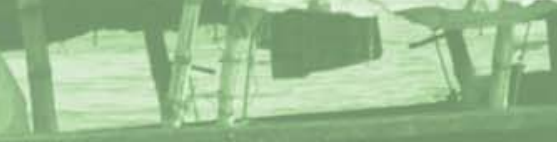
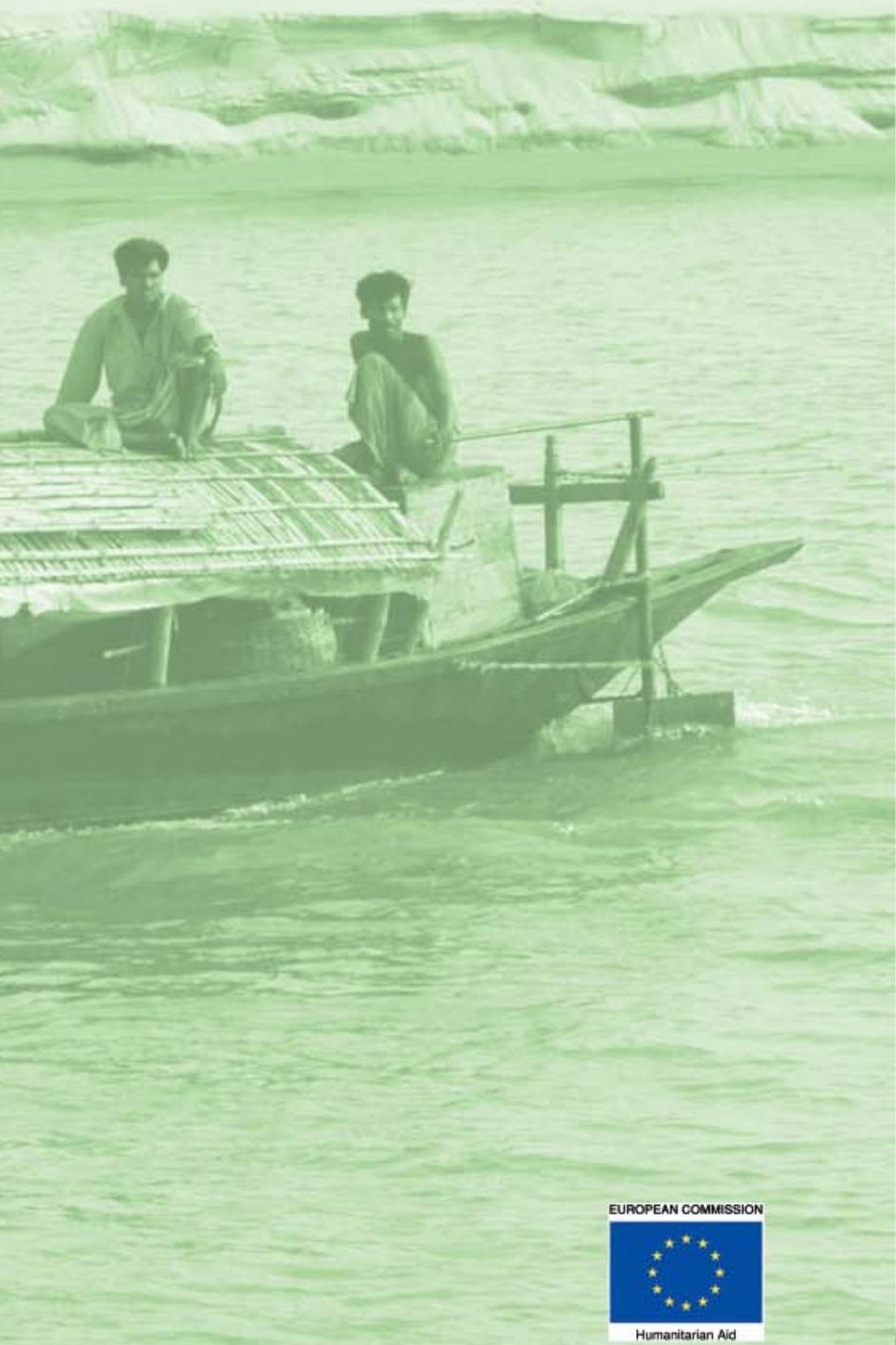

(C)ICIMOD 


\section{About the Organisations}

\section{International Centre for Integrated Mountain Development}

The International Centre for Integrated Mountain Development (ICIMOD) is an independent 'Mountain Learning and Knowledge Centre' serving the eight countries of the Hindu Kush-

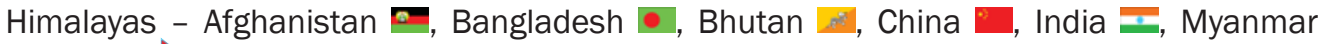
- Nepal $\mathbf{5}$, and Pakistan $\mathbb{C}$ - and the global mountain community. Founded in 1983, ICIMOD is based in Kathmandu, Nepal, and brings together a partnership of regional member countries, partner institutions, and donors with a commitment for development action to secure a better future for the people and environment of the extended Himalayan region. ICIMOD's activities are supported by its core programme donors: the governments of Austria, Denmark, Germany, Netherlands, Norway, Switzerland, and its regional member countries, along with over thirty project co-financing donors. The primary objective of the Centre is to promote the development of an economically and environmentally sound mountain ecosystem and to improve the living standards of mountain populations.

\section{European Commission Humanitarian Aid (ECHO)}

EUROPEAN COMMISSION

The European Union as a whole (i.e., the Member States and the

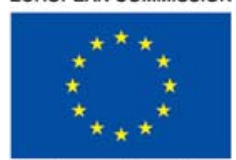
Commission) is one of the world's largest humanitarian aid donors; the Humanitarian Aid department (ECHO) is the service of the European Commission responsible for this activity. ECHO funds relief operations for victims of natural disasters and conflicts outside the European Union.

Humanitarian Aid Aid is channelled impartially, straight to victims, regardless of their race, religion, and political beliefs.

DIPECHO stands for disaster preparedness in ECHO. It supports projects aimed at increasing the resilience of communities at risk of natural disasters by funding training, capacity building, awareness raising, early warning systems, and advocacy activities in the field of disaster risk reduction. 


\section{Disaster Preparedness for Natural Hazards: Current Status in Bangladesh}




\section{Disaster Preparedness for Natural Hazards Current Status in Bangladesh}

A consultancy report by Khurshid Alam and Masroor-ul Haq Siddiqi

International Centre for Integrated Mountain Development (ICIMOD) Kathmandu, Nepal June 2007 


\section{Copyright (c) 2007}

International Centre for Integrated Mountain Development (ICIMOD)

All rights reserved

\section{Published by}

International Centre for Integrated Mountain Development

G.P.O. Box 3226

Kathmandu, Nepal

\section{ISBN 9789291150366}

Front Photo: Boats provide important means of transport in Bangladesh.

- Mats G. Eriksson

\section{Editorial team}

Mats G. Eriksson (Series Coordinator)

Greta M. Rana (Consultant Editor)

A. Beatrice Murray (Senior Editor)

Dharma R. Maharjan (Layout Design)

\section{Printed and bound in Nepal by}

Hill Side Press (P) Ltd.

Kathmandu

\section{Reproduction}

This publication may be reproduced in whole or in part and in any form for educational or non-profit purposes without special permission from the copyright holder, provided acknowledgement of the source is made. ICIMOD would appreciate receiving a copy of any publication that uses this publication as a source.

No use of this publication may be made for resale or for any other commercial purpose whatsoever without prior permission in writing from ICIMOD.

\section{Note}

The views and interpretations in this publication are those of the author. They are not attributable to ICIMOD and do not imply the expression of any opinion concerning the legal status of any country, territory, city or area of its authorities, or concerning the delimitation of its frontiers or boundaries, or the endorsement of any product.

This report was edited into the current form without further review by the author. 


\section{Contents}

Foreword $\quad$ V

Preface vii

Conclusions from the Regional Workshop on Disaster Preparedness Plans ix

Acknowledgements

Executive Summary

Acronyms and Abbreviations $\quad x v$

Glossary xvii

Some Key Terms $\quad$ xix

Chapter 1: Introduction $\quad 1$

Chapter 2: Background to Natural Hazards 3

Chapter 3: National Disaster Preparedness 13

Chapter 4: Disaster Preparedness Planning at National Level 21

Chapter 5: Planning at District and Community Levels 35

Chapter 6: Gaps in Existing Plans $\quad 39$

Chapter 7: Communicating and Sharing Knowledge $\quad 43$

Chapter 8: Conclusions and Recomendations $\quad 47$

$\begin{array}{ll}\text { Bibliography } & 49\end{array}$

Annexes (on CD-ROM in back pocket)

Annex 1: Terms of Reference

Annex 2: Standing Orders on Disaster

Annex 3: National Disaster Management Council

Annex 4: Inter-Ministerial Disaster Management Coordination Committee

Annex 5: $\quad$ National Disaster Management Advisory Committee

Annex 6: Draft National Plan for Disaster Management 2007-2015

Annex 7: $\quad$ Draft Disaster Management Act

Annex 8: Recommendations from the National Workshop on Options for Flood Risks and Damage Reduction in Bangladesh, 2004

Annex 9 : Ministries and Organisations Involved in Disaster Management 
T

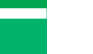




\section{Foreword}

Inhabitants in the Himalayan region are exposed to many natural hazards. The mountain ranges are young with an unstable geology, steep slopes, and a climate that is difficult to predict. As a result, the region is highly susceptible to natural hazards such as floods and flash floods, landslides, and earthquakes. In populated areas, these can lead to disaster. Vulnerable groups - the poor, women, and children - are often hit hardest.

Since its establishment in 1983, ICIMOD has dedicated much of its work to examining ways to reduce the risk of disasters from natural hazards, thereby working towards the decreased physical vulnerability of people in the Hindu Kush-Himalayas. This work has encompassed training courses, hazard mapping, landslide mitigation and control, mountain risk engineering, watershed management, vulnerability assessment, and much more. ICIMOD has also fostered regional and transboundary dialogue for improved management of both the resources provided and the risks threatened by the big rivers in the Himalayan region; sharing of hydro-meteorological data and information among the countries in the region is of particular importance for mitigating the risk of riverine and flash floods in the major river basins.

This publication is one of a series produced under the project 'Living with risk - sharing knowledge on disaster preparedness in the Himalayan region', implemented by ICIMOD during a 15-month period in 2006 and 2007. The project was funded by the European Commission through their Humanitarian Aid department (DG ECHO) as part of the Disaster Preparedness ECHO programme (DIPECHO) in South Asia, and by ICIMOD. Through this project, ICIMOD has endeavoured to encourage knowledge sharing and to strengthen capacity among key practitioners in the field of disaster preparedness and management. This has been done through training courses, workshops, knowledge compilation and dissemination, and the establishment of a website (www. disasterpreparedness.icimod.org).

The publications resulting from this project include baseline assessments of the disaster preparedness status in the four target countries (Bangladesh, India, Nepal, and Pakistan); case studies and a framework on local knowledge for disaster preparedness; and gender and vulnerability aspects in disaster risk reduction. The publications, training sessions, and workshops were undertaken in the context of the 'Hyogo Framework for Action 2005-2015' which recommends that regional organisations should promote sharing of information; undertake and publish baseline assessments of disaster risk reduction status; and undertake research, training, education, and capacity building in the field of disaster risk reduction. 
The long-term mission to bring the Himalayan region to an acceptable level of disaster risk has only just begun. The countries in the region are among the most disaster prone in the world in terms of number and severity of disasters, casualties, and impact on national economies. Only by strong commitment, hard work, and joint efforts can this situation be improved. It is ICIMOD's hope that our collective endeavours will help improve disaster risk reduction in the mountain region we are committed to serve.

Dr. Andreas Schild

Director General

ICIMOD 


\section{Preface}

This report is one of four status reports on disaster preparedness planning covering four countries; viz., Bangladesh, India, Nepal, and Pakistan. The purpose of these reports is to provide an opportunity for the reader to get a quick overview of the current status on documents in place and the institutions governing the implementation of these documents in the respective countries.

The reports are consultancies undertaken as part of the project 'Living with risk sharing knowledge on disaster preparedness in the Himalayan region', implemented by ICIMOD. It was funded by the European Commission through its Humanitarian Aid Department (DG ECHO) as part of the Disaster Preparedness ECHO Programme (DIPECHO) in South Asia, and by ICIMOD. The project takes off from the Hyogo Framework for Action 2005-2015 (HFA) which provides guidance on the roles regional organisations, such as ICIMOD, can play in long-term work towards reducing the risks of disaster. One recommendation by HFA is to undertake and publish baseline assessments of the status of disaster risk reduction.

As part of this project, a 'regional workshop on disaster preparedness plans' was held in Kathmandu in August 2006. The main objective of this workshop was to discuss the status of disaster preparedness as reflected in policies, strategies, plans, and other relevant documents available, or being developed, in the four countries. Particular interest was given to identifying gaps and shortcomings in the functioning and implementation of these guiding documents. First drafts of these country status reports were prepared for the workshop and formed the basis for the discussion and gap analysis. The reports have since been updated, improved, and extended. The outcome of the workshop was summarised in 15 concluding points, highlighting the status of disaster preparedness (DP), in particular, and disaster management (DM), in general, in the region. These 15 concluding points follow below.

The complete compilation of all documents at all governance levels, covering all types of disaster and providing full descriptions of all implementing institutions is an immense task, and it is beyond the scope of this project. ICIMOD has a mandate to focus primarily on mountain hazards, and therefore the scope of the consultancy has been to cover earthquakes, landslides, and floods, including flash floods (see Annex 1 for Terms of Reference). Furthermore, the study focused on documents and institutions governing disaster preparedness planning at the central, national level, with more limited coverage given to district and community levels. Hence, the reports are not 
exhaustive in terms of covering all natural hazards. Nevertheless, the documents and institutions governing disaster preparedness at the national level do, in many cases, take a multi-hazard approach. In conclusion, the present document will give the reader a good, albeit quick, overview of the status of disaster preparedness planning for natural hazards. As such, it is the hope of ICIMOD that it will prove helpful as a source of information and thereby support the joint efforts undertaken by many government and non-government organisations towards a Himalayan region that is better prepared to mitigate the impacts of disasters.

\author{
Dr. Mats G. Eriksson \\ Water, Hazards and \\ Environmental Management
}

ICIMOD 


\section{Conclusions from the Regional Workshop on Disaster \\ Preparedness Plans for Natural Hazards \\ (Kathmandu, 7-9 August 2006)}

\section{General Observations}

1. Disaster preparedness (DP) has to be approached holistically because it is difficult to isolate preparedness from other components of disaster management (DM) such as reduction, response, and recovery.

2. A paradigm shift in DM from a relief-driven approach to a more preparednessdriven approach is occurring.

3. Local communities should be at the centre of DM plans. They are the first victims of natural hazards and the first respondents.

\section{Development and Vulnerable Groups}

4. DM should be integrated into national development plans for improved sustainable livelihoods and poverty reduction.

5. A multi-hazard approach is crucial as most communities are exposed to hazards that have interacting and cascading effects.

6. Vulnerable groups and marginalised people are insufficiently addressed in DM plans.

\section{Institutions and Policies}

7. The political will to direct sufficient resources is essential for the efficient implementation of existing DM plans.

8. Planning for DM is an iterative process that should be based on the efficient use of already existing resources.

9. Roles and responsibilities for DM of all stakeholders at the national, regional, and local levels need to be clarified. DM should be a priority on the national political agenda.

\section{Knowledge and capacities}

10. Local knowledge should be respected and combined with other knowledge to improve the design and implementation of DM activities.

11. Learning from past disaster events through research and documentation is important in order to anticipate and respond to future disasters more effectively than is currently the case.

12. Education and training in DM is necessary for awareness and capacity building of all stakeholders.

\section{Communication and Cooperation}

13. Insufficient coordination prevails among key actor in the field of DM.

14. Functional and efficient communication among key actors at local, national, and international levels needs to be improved.

15. Data and information sharing at a regional transboundary level needs to be strengthened and requires appropriate capacity and technology. 


\section{Acknowledgements}

The work for this status report was commenced by Mr. Masroor-ul Haq Siddiqi and was then taken forward and completed by me. In this version, I have added my personal observations and analysis of the way disaster reduction policy and practices have been changing in Bangladesh. Many of my friends and colleagues have generously contributed ideas and support over a long period while the report was in the making. I am especially grateful to my long time friend A.K.M. Mamunur Rashid (Team Leader, Service Delivery of the Comprehensive Disaster Management Programme of Bangladesh) for his support and engagement. He has identified the right documents for me. Even more important, over the last few years, we have been engaged in debating on disaster risk reduction discourse and policies, how they are changing, and what new things may, and should, come up. These discussions have had a strong influence on this report. I am therefore very grateful to Mamun. I would also like to thank Naureen Fatima, my associate, for her great contribution in making the report presentable and useful for potential international and regional users.

The report has been prepared with active technical, financial, and intellectual support from ICMOD. Finally, I am grateful to Dr. Mats Eriksson for providing valuable comments on various drafts, and to the many other colleagues at ICMOD who carried out internal review and editing to make it a friendly report.

Khurshid Alam

Independent Researcher and Consultant

Disaster reduction, climate change, livelihood and governance specialist Dhaka, Bangladesh www.khurshidalam.org 


\section{Executive Summary}

This report provides key issues (not a comprehensive analysis, which is available in much of the literature) of disaster problems in Bangladesh, the history behind the current status of disaster preparedness plans, and gaps in the plans and shortcomings in their implementation. It also gives an account of disaster management instruments, institutional arrangements, and policies at national and local level. Finally, the authors give their own analysis of the key performance issues of implementation of the various plans.

The analytical framework used in the report has three core components: a) natural hazards are analysed taking into account that Bangladesh is located within the Himalayan or Ganges-Brahmaputra-Meghna (GBM) geophysical region; b) disaster preparedness plans are presented as they existed in February 2007, and c) various national and international commitments such as the Hyogo Declaration and the author's own long-term research into understanding people's vulnerability were the basis to comment on gaps in the plans as well as performance in their implementation. The exercise involved interviewing key people in Bangladesh. Some of the main points are summarised in the following passages.

Whereas Bangladesh has made good progress in human development in recent years, the majority of its population still live in poverty. The frequency and impact of natural hazards are among the key factors behind the great differences in the incidence of poverty at household level and in terms of geographical area. Poverty, disaster, and environment are strongly linked in Bangladesh in terms of impact on daily lives and on how successful the country is in achieving sustainable development and growth.

With the highest disaster mortality rate in the world (UNDP 2004), Bangladesh lost 516,239 men, women, and children from 1970 to 2005 in 171 disasters. The economic costs associated with such disasters continue to grow at national level, while the impact on livelihoods at household level remains unmeasured. The traceable economic cost of the 1991 cyclone alone, which killed 150,000 people, was US\$2 billion. Bangladesh faces at least one major disaster a year and more than one in some years. Twenty-one per cent of the country's land is flooded every year and the country suffered 16 major floods from 1954-2007.

The Government of Bangladesh lists floods, cyclones, earthquakes, tornadoes, river bank erosion, water logging, drought, salinity, storms, landslides, and tsunami as major disasters to which the country is vulnerable. The list also includes various other disaster 
trends such as industrial pollution, fire, epidemics, food-related disasters, and political violence. These disasters hit all the country's agro-ecological areas: floodplains and small hilly regions as well as urban centres.

Among the disasters, floods are the most frequent, and bring with them a heavy economic toll on the people and the country's economy compared to the less frequent cyclones, but they have a great impact in terms of casualties and economic activities. The earthquake risk is also high in Bangladesh, as it is located in a region that is an active seismic zone and which has experienced four great earthquakes in the last 100 years. Between 1869 and 1950, seven major earthquakes with magnitudes exceeding seven occurred in the region and had effects in Bangladesh.

The four core factors accounting for the vulnerability of Bangladesh and its population are location, climate change, governance, and people's vulnerability.

There is limited literature about public disaster preparedness (DP) approaches during colonial times. However, the understanding of disaster and its causes has been evolving from a perspective based on hazards to a focus on vulnerability; and this has greatly influenced the DP approach in the post-colonial period. Perspectives now include disaster response, structural mitigation, improving human skills and augmenting resources needed to cope with disasters, institutional efficiency, and, finally, a comprehensive approach.

Institutionally, Bangladesh has undertaken to establish a core foundation for DP. There is a good early warning system for cyclones and flooding. Investment in public health and safety nets has reduced disaster-related mortalities to a remarkable extent. There is a high level of awareness among the people about disaster preparedness because of national public awareness campaigns held by government and non-government organisations (NGOs). But are people safe? Poverty is still a key challenge to people's ability to invest in DP at the household level. Although life-saving measures are in place, livelihood protection is an issue that remains a challenge to the nation.

Although the institutional set up required for effective disaster preparedness and response is adequate at the national level, augmenting capacity and skills and decentralisation of authority are still priorities at local and district levels. The Ministry of Food and Disaster Management (MoFDM) is the main coordinating organ of the government directed by the National Disaster Management Council (NDMC) (headed by the Prime Minister) and Inter-Ministerial Disaster Management Coordination Committee (IMDMCC) to deal with disasters. The Disaster Management Bureau (DMB) is the focal point for disaster preparedness at national level, whereas various disaster management committees are responsible for DP at district, sub-district, and local level. 
Two key documents, i.e., Standing Orders on Disaster (SOD) and a comprehensive plan (draft) are the sources of clarity for the roles and responsibilities of the various institutions and personnel involved in disaster preparedness. However, there is no approved national policy on disaster preparedness, although the MoFDM has a corporate plan for comprehensive DM. This is an umbrella plan that outlines a multihazard approach, and it is pending approval from the Cabinet. The National Water Management Plan, which has a root in the Flood Action Plan (FAP), is the only hazard specific plan. The DMB has developed an Earthquake Preparedness Plan and the MoFDM a separate National Tsunami Risk Reduction Plan of Action. The Ministry of Public Works has enacted a national building code which includes a preparedness component against earthquake hazards. There is no specific earthquake plan.

Many of the disaster preparedness instruments are still in draft stage: some of them have been developed as part of big international and regional initiatives such as the South Asian Association for Regional Cooperation's (SAARC) Framework of Action and Hyogo Framework of Action (HFA).

Almost all the plans have been developed through techno-bureaucratic exercises with no participation from the many stakeholders. Therefore, linkages between poverty, gender, and the environment are missing. The four critical gaps in the plans and drafts are the fact that: a) they do not legally guarantee entitlements to the people after disasters, b) the accountability mechanism is not clear, in some cases there is no sanction mechanism if something goes wrong, c) there is no clear direction about coordinating other stakeholders in a common national goal, and d) they are not focused on community empowerment.

Six key factors accountable for the limited performance in terms of implementation include: a) vulnerable people and limited participation of non-state actors in planning exercises resulted in limited ownership and lack of a clear focus, b) lack of information at local level about the plans, c) no initiatives to scale up good approaches, d) limited decentralisation and devolution of power and resources to the local government level to implement local plans, e) perspective of (response led), leadership by, and commitment of government officials and politicians concerning disaster reduction, and f) limited capacity and resources at various levels.

Ownership of the plans is limited and has resulted in haphazard implementation by different stakeholders. Many good disaster reduction approaches tested by local organisations have not been integrated into a common national approach. Many of them are spread too thinly and have not been scaled up in all vulnerable areas. For example, the Comprehensive Disaster Management Programme (CDMP) is implementing national and local level plans in seven selected districts. 
Vulnerable people's access to information about policies is also limited, hindering implementation of plans at national level. People do not have information about plans developed at national level. There is no effective communication strategy to disseminate them.

Many plans have not been fully implemented and local-level leadership, such as the Union Disaster Management Committees (UDMCs), is not supported with the commensurate authority and resources. The widespread corruption is used as an excuse to not give funds to the Union Parishad (UP).

Limited work has been carried out on urban disasters and, because of the frequent recurrence of floods and cyclones, earthquake preparedness plans are yet to be implemented.

Decision-making is top down; therefore many local disasters get no response. Political considerations sometimes overshadow the vulnerability criteria of resource allocation for the implementing disaster preparedness plans. The risk reduction fund, established in 2004 , is given as an example.

There is no formal, common communication platform on DP. However, the Disaster Management Information Centre (DMIC) is a virtual centre for information exchange, and there are forums in which various stakeholders participate.

Although Bangladesh is one of the countries that provided leadership in the formulation of the Hyogo Declaration and Framework of Action, there is yet to be a multi-stakeholder national platform on the implementation of national priorities.

There are many laws and declarations guiding and binding countries on how to address disasters that are transboundary in nature. Floods and earthquakes in the Himalayan region are two disasters that have serious impacts on the lives of people and economies of countries, but until the $13^{\text {th }}$ SAARC Summit there was no effective declaration about how countries in the region could exchange information and solve their joint problems related to disasters. It was primarily because India perceived flooding to be a bilateral problem that a separate treaty was signed between Nepal and India. Post the Asian Tsunami, the $13^{\text {th }}$ SAARC Declaration acknowledged the need for a multilateral framework and agreed on a "permanent regional response mechanism dedicated to disaster preparedness, emergency relief and rehabilitation to ensure immediate response'. 


\section{Acronyms and Abbreviations}

\begin{tabular}{|c|c|}
\hline ADB & Asian Development Bank \\
\hline BMD & Bangladesh Meteorological Department \\
\hline BUET & Bangladesh University of Engineering and Technology \\
\hline BWDB & Bangladesh Water Development Board \\
\hline CBO & community based organisation \\
\hline $\mathrm{CCC}$ & climate change cell \\
\hline CCDMC & City Corporation Disaster Management Committee \\
\hline CDMP & Comprehensive Disaster Management Programme \\
\hline CPP & Cyclone Preparedness Programme \\
\hline CPPIB & Cyclone Preparedness Programme Implementation Board \\
\hline CRA & community risk assessment \\
\hline CSDDWS & $\begin{array}{l}\text { Committee for Speedy Dissemination of Disaster Related Warning/ } \\
\text { Signals }\end{array}$ \\
\hline DAE & Department of Agricultural Extension \\
\hline DC & Deputy Commissioner \\
\hline DDMC & District Disaster Management Committee \\
\hline DIRA & Disaster Impact and Risk Assessment \\
\hline DMB & Disaster Management Bureau \\
\hline DMC & Disaster Management Committee \\
\hline DMIC & Disaster Management Information Centre \\
\hline DoE & Department of Environment \\
\hline DRR & Directorate of Relief and Rehabilitation \\
\hline DRRO & District Relief and Rehabilitation Officer \\
\hline EIA & Environmental Impact Assessment \\
\hline EOC & Emergency Operation Centre \\
\hline FFW & Food for Work \\
\hline FFWC & Flood Forecasting and Warning Centre \\
\hline FPOCG & Focal Point Operation Coordination Group of Disaster Management \\
\hline GoB & Government of Bangladesh \\
\hline HFA & Hyogo Framework for Action \\
\hline IMDMCC & Inter-Ministerial Disaster Management Coordination Committee \\
\hline IMF & International Monetary Fund \\
\hline ICZMP & Integrated Coastal Zone Management Plan \\
\hline JRC & Joint Rivers' Commission \\
\hline MoFDM & Ministry of Food and Disaster Management \\
\hline MoWR & Ministry of Water Resources \\
\hline NAPA & National Adaptation Programme of Action \\
\hline
\end{tabular}


NDMAC National Disaster Management Advisory Committee

NDMC National Disaster Management Council

NGO non-government organisation

NGOCC NGO Coordination Committee on Disaster Management

NWMP National Water Management Plan

PDMC Pourashava Disaster Management Committee

SDMC SAARC Disaster Management Centre

SMRC SAARC Meteorological Research Centre

SOD Standing Orders on Disaster

UN United Nations

UNFCCC United Nations Framework Convention on Climate Change

UNO 'Upazilla' Nirbahi Officer

UZDMC 'Upazilla’ Disaster Management Committee

WARPO Water Resource Planning Organisation 


\begin{tabular}{|c|c|}
\hline ssar & military (adj.) \\
\hline bandh & a small earthenware embankment \\
\hline etar & $\begin{array}{l}\text { Bangladesh Betar, a broadcasting company effective at } \\
\text { relaying information to the grass roots, especially during } \\
\text { disasters }\end{array}$ \\
\hline haor & large saucer-shaped depression in the landscape \\
\hline kashful & vetiver grass \\
\hline khal & a small channel \\
\hline pourashava & Bengali term for small municipalities \\
\hline taka & $\begin{array}{l}\text { Bangladesh currency unit; there are approximately } 66 \text { taka } \\
\text { to the US dollar }\end{array}$ \\
\hline ana & $\begin{array}{l}\text { literally 'police station'; the lowest level of police } \\
\text { administration which contains one police station }\end{array}$ \\
\hline union & $\begin{array}{l}\text { the lowest seat of local government institutions; several } \\
\text { villages make a union }\end{array}$ \\
\hline upazilla & $\begin{array}{l}\text { the second tier of local government, a sub-district ('upa' } \\
\text { means sub and 'zilla' district); several unions form an } \\
\text { 'upazilla', most government field-level offices are coordinated } \\
\text { by an 'upazilla nirbahi' officer }\end{array}$ \\
\hline illa nirbahi officer & chief executive officer of a sub-district \\
\hline dar & landlord \\
\hline
\end{tabular}




\section{Some Key Terms}

Capacity - A combination of all the strengths and resources available within a community, society, or organisation that can reduce the level of risk, or the effects of a disaster.

Disaster - A serious disruption of the functioning of a community or a society causing widespread human, material, economic, or environmental losses which exceed the ability of the affected community or society to cope using its own resources.

Disaster risk reduction (disaster reduction) - The conceptual framework of elements considered with the possibilities to minimise vulnerabilities and disaster risks throughout a society, to avoid (prevention) or to limit (mitigation and preparedness) the adverse impacts of hazards, within the broad context of sustainable development.

Hazard - A potentially damaging physical event, phenomenon or human activity that may cause the loss of life or injury, property damage, social and economic disruption or environmental degradation.

Mitigation - Structural and non-structural measures undertaken to limit the adverse impact of natural hazards, environmental degradation, and technological hazards.

Preparedness - Activities and measures taken in advance to ensure effective response to the impact of hazards, including the issuance of timely and effective early warnings and the temporary evacuation of people and property from threatened locations.

Resilience/resilient - The capacity of a system, community or society potentially exposed to hazards to adapt, by resisting or changing in order to reach and maintain an acceptable level of functioning and structure. It is determined by the degree to which the social system is capable of organising itself to increase its capacity for learning from past disasters for better future protection and to improve risk reduction measures.

Risk - The probability of harmful consequences, or expected losses (deaths, injuries, property, livelihoods, economic activity disrupted, or environmental damage) resulting from interactions between natural or human-induced hazards and vulnerable conditions. Conventionally risk is expressed by the notation Risk $=$ Hazards $x$ Vulnerability. Some disciplines also include the concept of exposure to refer particularly to the physical aspects of vulnerability. A disaster is a function of the risk process. It results from the combination of hazards, conditions of vulnerability and insufficient capacity or measures to reduce the potential negative consequences of risk.

Risk assessment or analysis - A methodology to determine the nature and extent of risk by analysing potential hazards and evaluating existing conditions of vulnerability that could pose a potential threat or harm to people, property, livelihoods and the environment on which they depend.

Vulnerability - The conditions determined by physical, social, economic, and environmental factors or processes which increase the susceptibility of a community to the impact of hazards. 